\title{
QUADRINHOS EM SALA DE AULA: CONTRIBUIÇÕES DE DESIGN NO LETRAMENTO DA EDUCAÇÃO BÁSICA
}

Prof. Cristiana de Almeida Fernandes

Pontifícia Universidade Católica do Rio de Janeiro (PUC-Rio)

Universidad de Sevilla, Espanha

cristiannafernandes@gmail.com

Prof. Vera Lúcia dos Santos Nojima

Pontifícia Universidade Católica do Rio de Janeiro (PUC-Rio)

veluc.nojima@gmail.com

Prof. Ana Cristina dos Santos Malfacini

Universidade do Estado do Rio de Janeiro (UERJ)

Centro Universitário de Volta Redonda (UniFOA)

anamalfacini@hotmail.com

Prof. Jesús Jiménez Varea

Universidad de Sevilla, Espanha

jjvarea@us.es

Resumo: Este artigo traz alguns questionamentos e considerações presentes numa pesquisa centrada na tecitura de contribuições do Design que permitam a docentes do ensino básico utilizar o gênero literário quadrinizado (histórias em quadrinhos) na busca do letramento de seus alunos. São muitas as finalidades pelas quais as HQs, em conjunto com jogos e brincadeiras, têm sido reconhecidas como facilitadoras da assimilação e do dinamismo do conteúdo de mensagens intrínsecas, como também ferramenta lúdica para trabalhar diversos assuntos, entre eles, os temas transversais. Para Elydio Neto $(2015$, p.11) as histórias em quadrinhos são narrativas constituídas por escrita e desenho, que exigem de seus leitores interpretações visuais e verbais e, como dispositivos culturais, buscam construir uma reflexão que se torna um campo favorável à criatividade. A revista em quadrinhos - o gibi, por passar por um processo criativo e por meios de produção em série é produto do design, além de ser meio de comunicação com uma linguagem própria. Cada história e seus personagens são criados e desenvolvidos num projeto global que se constitui por passar por roteiro, desenho, arte-final, colorização, entre outros (BARI, 2008, p.56), podendo estar classificados em diversos subgêneros quadrinísticos, os quais os educadores muitas vezes desconhecem. A oferta de informações, conhecimentos e capacitação acerca do uso de histórias em quadrinhos, nos processos metodológicos calcados no Design, oportuniza ao docente conceber mecanismos didáticos que melhor aproveitem os recursos oferecidos por esse meio na 
alfabetização visual dos alunos.

Palavras-chave: Ensino, Design, quadrinhos.

\begin{abstract}
This paper aims to present questions and considerations that are part of a PhD research focused on the contributions of Design in the usage, by teachers, of comics in the literacy of elementary education students. Comics, together with games, are a recognized tool of multiple purposes by teachers, because consisting of a language of easy understanding and a message content dynamism, they work as a playful tool for various subjects, such as cross-cutting issues. To Elydio Neto (2015, p. 11), comics are narratives formed by writing and drawing that require their readers visual and verbal interpretations and, as cultural devices, they seek to build a reflection that becomes favorable for creativity. The comic book goes through a creative process and, together with the serial production, it becomes a product of Design, as well as a means of communication with its own language. Each story and its characters are created and developed within a global project that is formed by a script, design work, artwork and coloring, among others (BARI, 2008, p.56); and may be classified into several comic subgenres, which many educators are often unaware of. The provision of information, knowledge and training on the usage of comic books in methodological processes related to Design provide opportunities to teachers on learning mechanisms that best take advantage of the features offered by the comics in the visual literacy of students.
\end{abstract}

Keywords: Learning, Design, comics.

\title{
1 INTRODUÇÃO
}

Atualmente, usar quadrinhos em sala de aula, além de ser comprovadamente uma ferramenta que traz muitos benefícios no alcance do letramento na educação básica, é uma condição reconhecida, amparada e implementada pelo MEC. Existem algumas maneiras de aplicar conteúdos usando as HQs: com base na Lei de Diretrizes e Bases (LDB) (Brasil, 2013), através dos Parâmetros Curriculares Nacionais (PCNs), como recurso encontrado nos livros didáticos ou pelos materiais quadrinizados pertencentes às bibliotecas. No caso das escolas públicas, os livros de quadrinhos começaram a fazer parte dos acervos enviados pelo governo pelo Programa Nacional Biblioteca na Escola (PNBE) em 2006. Contudo, educadores do Brasil desenvolvem suas próprias ferramentas de trabalho com o uso dos quadrinhos, em sua maioria, trazidos pelos alunos.

Muito embora o PNBE realize entregas anuais à bibliotecas, é um programa que encontra muitas falhas no processo de implantação de atividades com esses livros. Tal crítica parte dos próprios professores que, logo nas primeiras avaliações do sistema, afirmaram não estar preparados o suficiente para sua utilização. Além disso, o MEC, mesmo alegando que o saldo dos primeiros anos de programa é "extremamente positivo", discute a verdadeira necessidade de treinamento do corpo docente: 
aos sistemas de ensino cabe incluir a formação do leitor em seu projeto político pedagógico e, para tanto, investir na formação de professores voltada para a realidade de cada município e ao projeto político pedagógico da escola. (SILVA in NAVEGA, 2011)

Silva (idem) conclui que "o município deve investir na formação do professor". Pode-se entender a partir disso, que há pouco conhecimento acerca das publicações existentes no acervo, desde os pais, docentes e até o prórpio MEC, resultando na má adequação desse meio. Segundo Santos e Vergueiro (2012, p.84), apesar de todo empenho dos professores e do MEC, "a utilização dos quadrinhos na educação ainda necessita de reflexões que subsidiem práticas adequadas e levem a resultados concretos em relação ao aprendizado".

Aparecida Paiva, responsável pela coordenação para a seleção de títulos que compõem a lista do PNBE (2011), prega pela necessidade de se investir na formação do leitor-professor para que "ele esteja em condições de exercer uma boa mediação de leitura". A coordenadora afirma que recebeu críticas dos docentes que utilizaram as obras, que se fundamentam em posições mais conservadoras sobre o texto literário, "pouco voltadas para a recepção do leitor pretendido, para a possibilidade de mobilizá-lo com uma linguagem que lhe seja mais atraente".

Além da porcentagem de quadrinhos ser ínfima em relação à literatura tradicional (livros ilustrados, livros de poesias etc), a quantidade de exemplares enviada às escolas é muito baixa em relação ao número de alunos. Segundo Bonino (idem), em 2009, dois anos após a inclusão dos quadrinhos nos acervos do PNBE, doze anos posteriores à criação do programa, somente dezesseis títulos, dos quinhentos e quarenta adquiridos faziam parte da coletivo, ou seja, $4,2 \%$ de quadrinhos em comparação com outros gêneros literários.

O acervo do PNBE é eleito com base na indicação de um corpo de professores, especialistas em literatura, leitura e educação e também pela contribuição de algumas escolas. Tais profissionais elegem os livros a partir de uma concorrência realizada pelas editoras, que seguem um edital do MEC. Vergueiro (2011) afirma

que no começo, a percepção do MEC foi de conceber as HQs como caminho ou degrau para a literatura tida como "mais nobre". Agora esse recorte perde espaço, até mesmo pelo aumento de obras indicadas que não são adaptações de obras literárias.

O autor conclui que, por mais que haja esse avanço no entendimento acerca da linguagem quadrinizada, grande foi o crescimento do gênero educativo no Brasil, uma vez que há uma aposta crescente por esse estilo por parte do MEC. Waldomiro (idem) avalia que "as editoras têm jogado no mercado milhares de adaptações", e, por mais que se forneça ao jovem uma narrativa mais atrativa baseada na história original, há de se tomar cuidado em seguir verdadeiramente a linguagem na qual os quadrinhos são reconhecidos, com diálogos dinâmicos, coerência de roteiros, sem que seja uma total transposição do objeto tradicional.

Paulo Ramos (2013), sobre o referido programa do governo brasileiro, considera que se prioriza o conteúdo literário que é explorado pela linguagem quadrinizada, mas não os quadrinhos em si: "é como se estes fossem usados apenas como ferramentas para incitar o aluno ao livro romanceado em que a obra foi 
baseada". O MEC e os professores vêem no quadrinho uma saída para uma atração ao hábito de ler e, por possuir uma linguagem mais acessível, "pode ser uma porta para o gênero literário". Contudo, Ramos (idem) conclui:

(...) consequência disso tudo é evidenciar que os quadrinhos estão sendo mal utilizados para contornar a inabilidade de se estimular a literatura dos clássicos literários, algo insubstituível.

Percebe-se por conseguinte que a presença de um objeto concebido para que tenha uma finalidade lúdica nas bibliotecas ou em salas de aula não significa que o problema do letramento se dê por finalizado. Pois, apesar dos professores terem alguma familiaridade com os gibis, a sua instrumentalização é necessária. Isso porque nas formações de professores, em que ocorrem aulas de didática e construção de ferramentas, pouco se aprende a respeito do uso dos quadrinhos para fins educativos, mesmo sabedo da sua eficácia.

Acredita-se que o melhor rendimento se obtém quando professor e aluno estabelecem um grau de relação no qual há uma troca de conhecimentos. Muitas vezes, o dispositivo trazido pelo aluno pode ser um potencializador narrativo dessa conjunção, fazendo o professor promover questionamentos a respeito do atrativo que o jovem tem com o enredo, figuras ou pelo próprio objeto literário. Com isso, é possível estabelecer a conexão quando se conhece de fato o material integrado ao ambiente escolar. Essa afirmativa se constata em um sem número de relatos de pessoas que afirmam ter aprendido a ler com os quadrinhos. Tal gênero narrativo pode ter sido apresentado ao jovem por seus pais ou pelos colegas. Quanto a isso, Demartini (2015, p.9) afirma:

(...) As histórias em quadrinhos têm uma história diferente de chegada às escolas - elas vêm dos alunos, do lado de fora da escola; foram entrando sorrateiramente em seus espaços, pulando os muros, passando de mão em mão pelos pátios, escondidas sob as carteiras, trocadas nos recreios, colecionadas em casa, mas ausentes nas bibliotecas até pouco tempo atrás.

Por um bom período as HQs eram sinônimo de subversão e, segundo documentações acerca da história desse meio, chegavam a ser queimadas nos pátios pelos padres e professores. Porém, parece que a proibição servia de desafio para os jovens, que eram levados a ler cada vez mais. Daí, esse gênero passou a ser bem difundido, dando margem à produção brasileira crescente até os dias de hoje, além das traduções advindas de outras nacionalidades.

No começo as histórias de heróis mais conhecidas foram trazidas dos Estados Unidos e, enquanto ali eram criadas, já havia materiais sendo difundidos no Brasil através dos jornais diários, com encartes específicos para esse meio. Porém, as produções nacionais ganhavam força à medida que as editoras investiam em tornar mais conhecidos os quadrinhos. Muitas revistas começaram a publicar, principalmente personagens que exploravam o universo infantil, com brincadeiras e travessuras. Por volta dos anos cinquenta, muitos gêneros já faziam parte do conhecimento dos jovens, desde os mais inocentes enredos até às histórias de conteúdo adulto. Isso fez com que o Brasil se tornasse um dos maiores produtores de quadrinhos do mundo. 
Também por volta dos anos cinquenta explode uma problemática, ao espelho de outros países ocidentais, quando as histórias em quadrinhos passaram a ser vistas como conteúdo que poderia subverter o comportamento do jovem. Itália, França e Espanha, por exemplo, à luz do que já vinha fazendo os Estados Unidos, tentavam impor regras de conduta para a confecção de material quadrinizado. Alguns mais radicais e outros menos, iniciativas governamentais ou do clero e outras privadas, iam criando seus códigos para não aventar suscetibilidades. Os conhecidos comic code americanos surgiram para barrar ou tornar permissíveis alguns conteúdos quadrinizados que vinham sendo perseguidos pela sociedade. Daí, para outras nacionalidades criarem as suas próprias regras foi uma questão de tempo. Essa perseguição também era justificada pela tentativa de alguns países de nacionalizar o aprendizado e as histórias americanas poderiam incutir ideias infratoras na cabeça do adolescente, dando-lhes hábitos estrangeiros.

Sem a tentativa de tecer julgamentos acerca das condutas adotadas e sobre o ferimento ou não da primeira regra da democracia, que é o "direito de expressão", naquele momento emerge com mais afinco uma espécie de leitura permitida dos quadrinhos, conhecida como "quadrinhos educativos". Criações como as tais adaptações literárias, transições trazendo histórias reais como a vida dos heróis republicanos, narrativas sobre a vida dos santos da igreja católica ou simplesmente personagens infantis com bom comportamento aparecem, fazendo com que os membros do poder descobrissem a potencialidade dessas histórias como arma política. Além disso, essa foi a saída para que as editoras, perseguidas pelas ditaduras em alguns países não fechasse as portas.

Por mais que o estilo educativo tenha proficiência ideológica, chegando a ser explorado pelos membros do governo para transmitir as suas ideias, os quadrinhos, como afirmam Vergueiro e Santos (2014, p.177) sempre tiveram uma finalidade de entretenimento, com um viés educacional sob a ótica dos editores. Hoje, por mais que haja grande repercussão sobre seus benefícios, é uma iniciativa governamental um pouco tardia, pois as crianças e jovens sempre foram apreciadores dos quadrinhos, sobretudo no Séc. XX.

Muito se discute a respeito da perda do hábito de ler por parte das crianças, principalmente por causa da grande incidência e proliferação dos jogos eletrônicos. Há também a crença de que o crescimento dos dispositivos está fazendo com o que os jovens migrem para outras plataformas, senão o papel. Contudo, a tecnologia sempre foi um tabu a ser discutido no ambiente educacional, pois se sabe que o jovem da atualidade cresceu inserido nas mídias eletrônicas, assim como sempre teve facilidade com as novas linguagens. Pode-se dizer que os quadrinhos hoje são lidos em quantidades através da internet ou com o uso de tablets/celulares. Ainda assim, muitos vídeojogos atuais carregam elementos visuais muito próximos dos usados nesse meio, como balões de fala, signos de movimentação e narrações escritas. Assim como os quadrinhos "beberam na fonte" do cinema, com seus enquadramentos e noções de corte de cena, por exemplo. Vergueiro (2013, p.37), afirma que há diálogos entre diferentes mídias e é importante que elas mantenham "características autônomas".

O pesquisador Flávio Calazans (apud BONINO, 2008) assegura que apesar da crescente utilização dos quadrinhos em sala de aula pelos docentes, muitos ainda encontram resistência. Isso se dá pelo fato de que "grande parte cresceu coma ideia 
de que não é leitura indicada". Ainda pontua: "É necessária uma alfabetização dos professores para que consigam usar os quadrinhos com toda a sua potencialidade" (CALAZANS, 2008, p. 8). Vergueiro (2013, p.76) alerta para o fato de que os educadores, de verdade já tiveram a crença de que os quadrinhos afastariam os jovens da leitura dos "livros de verdade", estimulando a "preguiça mental", podendo trazer riscos ao rendimento escolar dos alunos, mas isso vem mudando.

A maneira de se comunicar visualmente multiplica as possibilidades e utilidades de expressão. Nesse sentido, há a premissa de que professores do ensino básico devem conhecer a linguagem visual como artifício; os docentes devem ser alfabetizados visualmente, conhecendo os mecanismos para produzir recursos pedagógicos, de forma a perceber que os quadrinhos são indicados para o trabalho dessa instrumentalização. Dondis $(2007$, p.20) pontua que linguagens são sistemas inventados pelo homem para codificar, armazenar e decodificar informações. E se o Design é a área que se encarrega de projetar sistemas com a mesma finalidade, justifica-se a realização do presente ensaio como contribuição para os estudos da linguagem do Design.

\section{DESENVOLVIMENTO - NARRATIVIDADE: PRESSUPOSTOS E CONFLUÊNCIAS}

Muito mais do que um método a ser criado no auxílio de docentes no uso de quadrinhos, é necessário que esses tenham o reconhecimento de que existem muitas práticas a serem adotadas em sala de aula, que na grande maioria das vezes, são criadas pelos seus próprios colegas. Além disso, assim como afirma Demartini (2015, p.9):

é preciso alfabetizar-se na linguagem das histórias em quadrinhos, nas especificidades dessa narrativa, que geralmente envolvem desenho e escrita, para conhecer seus limites e possibilidades e, assim, melhor trabalhar com as mesmas.

Corroborando com o que diz Ramos (2014, p.31), essa alfabetização "é indispensável para que o aluno decodifique as múltiplas mensagens neles presentes e, também, para que o professor obtenha melhores resultados em sua utilização". Nessa perspectiva, vale registrar que o vocábulo alfabetismo se relaciona com o significado de letramento, que um grupo de educadores compartilha como uma maneira de relacionar informações. Donis A. Dondis $(2007$, p.3) cunha o termo para enfatizar a necessidade que o ser humano possui de dominar diversas linguagens. Dondis denomina como alfabetização visual a possibilidade de universalizar a linguagem: "construir um sistema básico para a aprendizagem, a identificação, a criação e a compreensão de mensagens visuais que sejam acessíveis a todas as pessoas". Barbosa (2014, p.31) afirma que alfabetização, especificamente falando de quadrinhos, é indispensável para a decodificação das múltiplas mensagens contidas nos quadrinhos por parte dos professores e alunos.

O problema que se apresenta é entender a maneira como a história da criança pode ser utilizada como dispositivo narrativo, com o artifício do quadrinho, sob forma de objeto narrativo em que esse é gênero. Além disso, também como pressuposto, saber quem são os agentes nesse processo, respeitando cada experiência no fluxo do aprendizado. Pois, só é possível falar sobre discurso a partir de como essa narrativa é 
montada.

Falar de ensino básico nos dias de hoje é quase uma obrigação dos profissionais envolvidos na formação de um indivíduo. Dizer que certo educador foi responsável pela instrução de alguém é um dado pouco convincente em um mundo tão complexo para a criança.

Acredita-se que o comportamento humano se baseia em experiências, pois dependerá de quem ele se "espelha" para a definição de seu caráter, por meio da linguagem. Além disso, essas experiências acontecem pela troca, pela tradição. Segundo Bakhtin (1997, p.313), "a experiência verbal individual do homem toma forma e evolui sob o efeito da interação contínua e permanente com os enunciados individuais do outro".

Segundo Waldomiro Vergueiro (2014, p.74), "infelizmente, apesar do esforço e boa vontade da maioria dos professores, grande parte de nossas crianças e adolescents demonstram desinteresse pelos conteúdos trabalhados nas diferentes disciplinas escolares". Torna-se então, um grande desafio para o professor, fora despertar o interesse, em desenvolver trabalhos que busquem mais dinamismo.

Os conteúdos programáticos do ensino básico são montados com base nas diretrizes curriculares nacionais (DCNs) propostos pelo governo, que preveem o aprendizado pelo artifício da ludicidade, pois, através das interações o indivíduo se constitui não tão somente como ele mesmo, mas também em relação com o grupo.

Um aspecto essencial do aprendizado é o fato de ele criar zonas de desenvolvimento proximal; ou seja,

(...) desperta vários processos internos de que são capazes de operar somente (na interação entre) pessoas em seu ambiente e quando em cooperação com seus companheiros. Uma vez internalizados, esses processos tornam-se parte das aquisições do desenvolvimento independente. (Vygotsky, 1994: 101)

Pois, se não é brincando que a criança aprende, se não é pelo entretenimento que o jovem faz suas escolhas, então, há uma questão ao presente. Poderia então o quadrinho, com sua história, construída com base em enunciados, entreter e educar ao mesmo tempo? Pois não, um artifício utilizado pelas professoras e pelos pais, é o quadrinho um objeto lúdico?

Encontra-se um sem número de relatos a respeito de como as histórias em quadrinhos auxiliaram na alfabetização e na construção do letramento. Pois bem, há no argumento e na narrativa do quadrinho um discurso, uma história, que auxilia nessa construção da própria história do indivíduo, que vai além de uma simples montagem gráfica constituída por elementos que trazem sentido, como balões de diálogo e sinais gráficos, com seus requadros e timings. O quadrinho, como mídia, traz consigo uma narrativa para entreter. Mas como utilizar um objeto que já está presente no imaginário da criança, com o propósito de contribuir para sua educação em um momento em que há uma legislação preocupando-se em afastá-lo?

É complexo o ato de educar, bem como escolher recursos para apoiar o ensino. Por isso chamamos esta etapa no processo de "pressupostos e confluências", pressupostos são as verdades as quais se acredita ser as melhores para se ensinar, tomando como ponto de partida a afirmativa de que o ato de se ensinar é um fenômeno de comunicação. 
As confluências são os cruzamentos das rotas existentes na confecção desse enorme tecido, acreditando que o objeto quadrinho é um auxiliador preponderante nesse processo. Afinal, há verdades por trás de cada argumento. Por que não haver uma próxima construção de mais uma verdade? Mito ou não, é o que aqui se acredita e esse é o pressuposto para traçar esses caminhos, ou seja, em busca de um novo eixo paradigmático.

Para tanto, há a necessidade de se ouvir os agentes envolvidos no ato de educar pelo quadrinho, ou a partir dele, ou por ele enquanto interface midiática. Longe de ser uma conjectura, educar pelos quadrinhos é reconhecer que existem histórias que, no mínimo servem de inspiração para a produção de seu argumento. Portanto, pressupõe-se que há discursos empregados nessas produções quadrinísticas, que auxiliarão mais tarde, na vivência, ou seja, na cultura do sujeito. É como se necessitássemos da lexis para documentar essas vivências.

Um pouco diferente do que relatar enquanto se executa a atividade, há a necessidade de colher as informações dos agentes educadores através do relato de suas experiências, pois são eles que traçam esses caminhos e que fazem as escolhas das interfaces que os auxiliam, isto é, os professores utilizam o conteúdo dessas histórias em quadrinhos para contribuir com as futuras experiências do indivíduo. Longe de ser uma tentativa de controle, é a partir desse conhecimento que se extrairá a essência, o substrato para as pesquisas que se seguem.

Assim, em busca de uma questão epistemológica, se necessita reconhecer que o Design é uma área que vai em busca da visão das experiências de alguém, para que, a partir de uma tradução, aponte caminhos possíveis para contribuir com a resolução de problemas, como uma ciência sim, e não somente um simples saber:

(...) todo um conjunto de conhecimentos metodicamente adquiridos, mais ou menos sistematicamente organizados e susceptíveis a serem transmitidos por um processo pedagógico de ensino. (JAPIASSU, 1979)

Não cabe aqui o questionamento de um pressuposto científico com a tentativa de posicionar o Design na área das ciências humanas, sociais ou exatas, até porque há teorias incumbidas e direcionadas a possíveis conclusões nesse sentido, sob a ótica de diversos autores. Porém, o que se pretende é entender que tal proposta que se segue, se calcará em um pensamento epistemológico do campo, como uma tentativa, um complemento e possíveis desdobramentos. Pois, não há de se negar que as metodologias projetuais do Design são respeitadas e utilizadas em diversas áreas, reconhecendo que essas também "emprestam" ao design suas regras e seu ferramental.

Para esclarecer a respeito dessa transversalidade, recorremos aos estudos acerca da estrutura rizomática em platôs de Deleuse \& Guatari (1997, p.15):

Num rizoma, cada traço não remete necessariamente a um traço linguístico: cadeias semióticas de toda natureza são aí conectadas a modos de codificação muito diversos, cadeias biológicas, políticas, econômicas etc, colocando em jogo não somente regimes de signo diferentes, mas também estudos de estados das coisas.

Cabe como um pressuposto o intenso número de relatos dos professores acerca 
do desinteresse dos alunos pelas atividades em sala de aula. Isso nos leva a crer que há um comportamento recíproco nessa dinâmica, uma vez que falar aos ouvidos do seu interlocutor é uma atitude prévia no sistema de comunicação. E se o jovem de hoje se interessa muito mais pelos dispositivos eletrônicos do que pelo conteúdo das disciplinas, há um desafio aos educadores.

Para esclarecer a respeito dessa questão é importante ressaltar que não se trata de uma narrativa de verossimilhança, apontada por Julio Plaza como diacrônica (2003, p.1), como aquela que é contada com causa e consequência. Que sirva de alerta ao presente que esse tipo de história, apesar de ser importante para a estrutura, seguindo até uma sequência de fatos, pouco nos interessa em se tratando do gênero quadrinho. Isso porque tal objeto possui recursos gráficos que seguem um roteiro e demandam um conhecimento prévio de seu código. Ou seja, assim como qualquer gênero, a montagem é o grande diferencial da narrativa e, para atrair o jovem, é necessário que a história esteja contextualizada, para que os quadrinhos cumpram seu verdadeiro papel.

Waldomiro Vergueiro $(2014$, p.37) alerta para a necessidade de se fazer "boas" escolhas para que se mantenha o jovem atraído pelo contexto a ser trabalhado. Segundo o autor, cada gênero possui a sua particularidade e é um erro fazer adaptações como as literárias, por exemplo, quando essas não seguem o ritmo, a quantidade de textos nos balões e uma sequência lógica. Citamos tais adaptações uma vez que é para elas que os programas governamentais direcionam seus maiores incentivos.

Diálogos entre as linguagens ocorrem. E também acontecem com o cinema, o teatro, a ilustração. Nem por isso deixam de manter suas características autônomas. Ou será que alguém espera encontrar balões em um romance? Não. Pois balões são uma convenção característica da linguagem dos quadrinhos. (VERGUEIRO, 2014, p.37)

Calazans (2008, p.20) afirma que os quadrinhos autorais são os que melhor aproveitam a linguagem quadrinizada, pois os autores não têm preocupação em adaptar, e sim, seguir um roteiro, criado por eles mesmos, com seu próprio desenvolvimento de personagens e argumentos. Do outro lado da moeda, aqueles a quem se destina o o quadrinho tem, segundo o mesmo autor, ainda atenta para o fato de que cada aluno possui um ritmo de leitura diferente, dependendo de sua escola e até da região onde está localizada.

É necessário portanto, com base nas afirmativas apresentadas, que se reconheçam as especificidades quadrinísticas como uma maneira de apresentar subsídios para auxiliar nessas escolhas em que o estudo da narrativa é o melhor caminho: dos pressupostos às confluências.

Para se começar um estudo sobre a narratologia é importante reconhecer que por trás de toda história a ser contada, há um discurso presente e, a intenção de se ter os quadrinhos presentes em sala de aula é de fato o pressuposto de que eles auxiliam no letramento.

É comum nas histórias mais tradicionais a presença de personagens infantis frequentando a escola, assim como há muitas personagens encarregadas por tomar o papel de professores. Esses papéis foram definidos talvez porque os quadrinhos sempre fizeram parte do universo da criança e há o compromisso de que personagens com uma certa idade estejam frequentando as aulas. 
O problema que agora se apresenta é o fato de que os professores em sala de aula estão cada vez mais desafiados a apreender a criança, uma vez que sua atenção compete com todos os mecanismos eletrônicos, gadgets e videogames. Há uma relutância iminentemente crescente em se deixar esses dispositivos for a do alcance do jovem, uma vez que "atrapalham" o bom rendimento e o bom andamento do aluno.

\section{CONCLUSÃO}

Muito se diz a respeito do desinteresse pela leitura principalmente por estudantes do ensino básico. A literatura tradicional sugerida disputa a atenção com jogos eletrônicos, mídias sociais e até com o próprio meio social da criança. Porém, acreditase que muitos desses jovens, em contato com a linguagem dos quadrinhos, adquirem benefícios para o seu aprendizado.

É comum encontrarem-se em prateleiras de lojas e em vendas on-line literaturas tradicionais adaptadas, objetos educativos de saúde, instruções técnicas e até peças gráficas para o ensino religioso com a linguagem das histórias em quadrinhos. É visível esse reconhecimento não somente pela sequência em quadros, como também pela presença de sutis balões de diálogo, ilustrações simplificadas, expressões de personagens, objetos de cenário, jogos de cores, sinais gráficos de movimentação ou entrada em cena pelas personagens, que, fatalmente, suscitam um contato com os aspectos da banda desenhada. Isso sem falar nos jogos de tabuleiro, jogos eletrônicos e adaptações cinematográficas, que sugerem a criação de novos produtos que vão desde gêneros alimentícios, passando por peças de vestuário, até brinquedos, mobiliário etc, que levam pelo menos a chancela de uma personagem consagrada, fazendo com que a indústria dos quadrinhos movimente nacional e internacionalmente milhões de dólares.

Dessea forma a ludicidade pode estar presente tanto nos jogos e brincadeiras, quanto em objetos de leitura que combinam texto e imagem, e por isso, os quadrinhos são reconhecidos como uma maneira muito eficaz de contar histórias e estimular a criatividade. As imagens sequenciadas também fomentam a atividade conjunta, pois atuam como mediadoras no processo de ensino-aprendizagem.

Pais e professores têm notado que crianças que leem quadrinhos são estimuladas a, futuramente, lerem outros gêneros literários. Porém, o governo brasileiro só sugere a presence dessa mídia nas salas de aula como artifício para o ensino em acervos do PNBE.

Para o pesquisador Flávio Calazans (2008, p.21), a adoção de um material quadrinizado como recurso paradidático deve ater-se aos quesitos que prendam a atenção do leitor. Para que isso ocorra, é necessário que o objeto quadrinho "reproduza a signagem, o visual, a estética e o ritmo narrativo ao qual os alunos estão habituados em sua leitura espontânea". Calazans ainda alerta para a existência de drama, verbo, ação e movimento, além de um colorido rico em todas as páginas, com uma linguagem acessível.

Um olhar detalhado do professor direcionado aos livros de quadrinhos que já se encontram à disposição das escolas é fundamental para a seleção e uso desse material. Contudo, é também muito importante que o docente possua letramento verbal desenvolvido e, principalmente, intimidade com a mídia sugerida. 
Nessa perspectiva, observou-se uma lacuna a ser preenchida no reconhecimento e no consequente estabelecimento de estratégias por parte dos docentes que utilizam os quadrinhos como recurso didático. É reconhecido que professores do ensino básico já empregam, recursos oferecidos por obras conhecidas e de difusão nacional e internacional para estimular os alunos à leitura. No entanto, é muito comum que, no início do ano letivo, não se encontre sequer uma unidade da Turma da Mônica, por exemplo, nas prateleiras dos sebos.

Em visitas à escolas do interior do Estado do Rio de Janeiro, constatou-se que além do acervo recebido não estar adequadamente posicionado, às vezes, não se encontra disponível livremente aos alunos. Além disso, quando se desenvolve uma maneira impositiva de aplicação desse material, há a danificação dos livros por parte dos estudantes.

Munari (1997, p.8) diz que no ensino estático, com programas fechados, "criase muitas vezes um sentimento de mal-estar e até de rebelião por parte dos estudantes". Em alguns casos, pode-se arriscar que o aluno, ao não perceber o encontro das práticas aos seus verdadeiros interesses, pode abandonar a escola. Já no ensino dinâmico, professores se direcionam ao aprendizado, partindo do entendimento das políticas, adequando os seus conteúdos e criando novos artifícios quando os interesses vão aparecendo. Segundo Munari (idem), "o professor deve ter elasticidade e rapidez para preparar as aulas com consequência das necessidades que se vão apresentando segundo a natureza de vários indivíduos".

Para chegar ao desenvolvimento de uma proposta baseada em parâmetros para a utilização dos recursos quadrinísticos pelos professores do ensino básico, é determinante conhecer e aplicar os pressupostos teóricos oferecidos pelo Design (Comunicação Visual: projeto gráfico, elementos visuais e elementos de construção de sentido) para a instrumentalização sistemática de futuros docentes. Munari ainda afirma que o tema Comunicação Visual é muito vasto, que vai do desenho até a fotografia; aplicado das artes plásticas até o cinema; utilizando desde formas abstratas até as reais; vão de imagens simples a imagens complexas.

\section{REFERÊNCIAS}

BAKHTIN, Mikhail. Estética da criação verbal. 2. ed. São Paulo: Martins Fontes, 1997.

1999.

Marxismo e filosofia da linguagem. Rio de Janeiro: Annablume Editora,

BARBOSA, Alexandre; RAMOS, Paulo; VILELA, Túlio; RAMA, ANGELA; VERGUEIRO Waldomiro. Como usar as histórias em quadrinhos na sala de aula. 4 ed. São Paulo: Contexto, 2014.

BARI, Valéria Aparecida. O potencial das histórias em quadrinhos na formação de leitores: busca de um contraponto entre os panoramas culturais brasileiro e europeu. São Paulo: Escola de Comunicação e Artes - ECA/USP, 2008.

BONINO, Rachel; VERGUEIRO, Waldomiro. Onomatopeia, imagem e ação. São Paulo: Revista Educação, 2011. Disponível na internet por http em: <http://revistaeducacao.uol.com.br/formacao-docente/144/artigo234570-1.asp>. Acesso em 15 mai. 2014.

BRASIL. Ministério da Educação. Secretaria de Educação Básica. Secretaria de Educação 
Continuada, Alfabetização, Diversidade e Inclusão. Conselho Nacional da Educação. Diretrizes curriculares nacionais gerais da educação básica / Ministério da Educação. Secretaria de Educação Básica. Diretoria de Currículos e Educação Integral. - Brasília: MEC, SEB, DICEI, 2013.

CALAZANS, Flávio. Histórias em quadrinhos na escola. 3 ed. São Paulo: Paulus, 2008.

CIRNE, Moacy; MOYA, Álvaro de; D’ASSUNÇÃO, Otacílio; AIZEN, Naumim. (org.) Literatura em quadrinhos no Brasil. Rio de Janeiro: Nova Fronteira / Fundação Biblioteca Nacional, 2002.

CIRNE, Moacy. Quadrinhos: sedução e paixão. Rio de Janeiro: Vozes, 2000.

DELEUSE, Gilles. Cinema: a imagem-movimento. São Paulo: Brasiliense, 1983.

DONDIS, Donis A. Sintaxe da linguagem visual. Tradução Jefferson Luiz Camargo. 3 ed. São Paulo: Martins Fontes, 2007.

EISNER, Will. Quadrinhos e arte sequencial. Tradução Luis Carlos Borges. São Paulo: Martins Fontes, 1995.

Editorial, 2008.

Produção textual, análise de genros e compreensão. São Paulo: Parábola

MCCLOUD, Scott. Desvendando os quadrinhos. São Paulo: Makron, 2005.

NAVEGA, Telio; SILVA, Jane Cristina. Quadrinhos no PNBE: o Ministério da Educação responde. São Paulo: O Globo Blog, 2011. Disponível na internet por http em: <http://oglobo.globo.com/blogs/gibizada/posts/2011/10/10/quadrinhos-no-pnbeministerio-da-educacao-responde-410331.asp>. Acesso em 23 abr. 2014

NETO, José Elydio dos Santos et. Al. Histórias em quadrinhos e práticas educativas, volume II: os gibis estão na escola, e agora? São Paulo: Criativo, 2015.

PLAZA, Julio. Tradução intersemiótica. São Paulo: Perspectiva, 2003.

RAMOS, Paulo. O negócio dos quadrinhos. Disponível na internet por http em: $<$ http://observatoriodaimprensa.com.br/feitos-

desfeitas/_ed763_o_negocio_dos_quadrinhos/>. São Paulo: Carta na Escola, n. 79, 2013. Acesso em 11 mai 2014.

SANTOS, Roberto Elísio; VERGUEIRO, Waldomiro. Histórias em quadrinhos no processo de aprendizado: da teoria à prática. Comunicação \& Educação, São Paulo, ECA-USP, n.27, p.81-95, jan/abr, 2012.

A revista Gibi e a consolidação do mercado editorial de quadrinhos no Brasil. Matrizes, São Paulo, ECA-USP, n.2, vol.8, p. 175-190, jan/jun, 2014.

VERGUEIRO, Waldomiro; RAMOS, Paulo. Quadrinhos na educação: da rejeição à prática. São Paulo: Contexto, 2013.

VYGOTSKI, Lev Semenovich. Pensamento e linguagem. Tradução Jefferson Luiz Camargo. 2. ed. São Paulo: Martins Fontes, 2003a.

A formação social da mente. São Paulo: Martins Fontes, 1994. 